\title{
BMJ Open Impact of handgrip strength on cardiovascular, cancer and all-cause mortality in the Korean longitudinal study of ageing
}

\author{
Gyu Ri Kim, ${ }^{1}$ Jiyu Sun, ${ }^{2}$ Minkyung Han, ${ }^{3}$ Sohee Park, ${ }^{4}$ Chung Mo Nam ${ }^{2}$
}

To cite: Kim GR, Sun J, Han M, et al. Impact of handgrip strength on cardiovascular, cancer and all-cause mortality in the Korean longitudinal study of ageing. BMJ Open 2019;9:e027019. doi:10.1136/ bmjopen-2018-027019

- Prepublication history and additional material for this paper are available online. To view these files, please visit the journal online (http://dx.doi. org/10.1136/bmjopen-2018027019).

Received 2 October 2018 Revised 14 March 2019 Accepted 19 March 2019

Check for updates

(C) Author(s) (or their employer(s)) 2019. Re-use permitted under CC BY-NC. No commercial re-use. See rights and permissions. Published by BMJ.

${ }^{1}$ Department of Biostatistics, Yonsei University Graduate School of Public Health, Seoul, The Republic of Korea

${ }^{2}$ Preventive Medicine, Yonsei University College of Medicine, Seoul, The Republic of Korea

${ }^{3}$ Department of Public Health, Yonsei University Graduate School of Public Health, Seoul, The Republic of Korea ${ }^{4}$ Department of Preventive Medicine, College of Medicine, Yonsei University, Seoul, The Republic of Korea

Correspondence to Dr Chung Mo Nam; cmnam@yuhs.ac

\section{ABSTRACT}

Objective To examine whether reduced handgrip strength, as a marker of muscle weakness, is linked with the risk of cardiovascular, cancer and all-cause mortality among older adults.

Design We used data from the 2006 to 2014 Korean Iongitudinal study of ageing study. Estimates of handgrip strength were collected using a handheld dynamometer. Cox proportional hazard models with time-varying covariates were used to estimate HRs and their 95\% Cls for all-cause mortality. The cause-specific hazards regression analysis was also used to model cardiovascular and cancer mortality, by treating deaths from the cause of interest as events and other causes of death as censored. Participants 5859 participants aged 50 years or older were followed up until death or until the date of censoring (31 December 2014).

Primary outcome measures The study outcomes of interest were all-cause, cardiovascular and cancer mortality.

Results Of the participants included in analyses, 515 individuals (8.8\%) died, reflecting an overall crude mortality rate of 11.0 deaths per 1000 person-years. Participants in the lowest handgrip strength tertile showed an increased risk of all-cause and cardiovascular mortality evidenced by a multivariable adjusted HRs of $1.90(95 \% \mathrm{Cl}$ 1.33 to 2.73 ) and 1.59 (95\% Cl 1.08 to 2.34$)$, respectively. However, there were no significant differences in the rates of cancer-related death, with HR of 1.29 (95\% Cl 0.92 to 1.81 [lowest vs highest tertile; $p$ trend $=0.21]$ ).

Conclusion These results demonstrate that lower handgrip strength is an independent predictor of mortality among a population-based sample of Korean elderly; highlighting the importance of interventions targeted at enhancing muscle strength for improvements in survival at older ages.

\section{INTRODUCTION}

With global population ageing and increases in longevity observed over the past few decades, increasing attention is being given to the importance of muscular strength, a physiological variable, that is, fundamental for maintenance of functional ability in later life. ${ }^{1}$ A growing body of research demonstrates that

\section{Strengths and limitations of this study}

To the best of our knowledge, this study is the first long-term follow-up study to demonstrate the prognostic role of handgrip strength for mortality in the Korean elderly population.

- The use of an objective and standardised test for the assessment of muscular strength and the nationally representative population-based sample.

- Owing to the limits of the sample size, cause-specific analyses were restricted to cardiovascular and cancer mortality. Future studies should further explore other causes of death.

muscular strength, as measured by handgrip strength shows a decreasing correlation with age and is associated with a variety of health outcomes, including disability, ${ }^{2}{ }^{3}$ hospitalisation, ${ }^{4}$ health-related quality of $\operatorname{life}^{5}$ and survival in diverse samples of older adults. ${ }^{6-10}$ According to a recent meta-analysis of 42 prospective cohort studies, lower handgrip strength is associated with $41 \%$ excess risk of dying from all causes, even after adjustment for several confounders including levels of physical activity and pre-existing comorbidities. ${ }^{11}$ Furthermore, similar associations have been reported in several patient populations, suggesting that muscular strength protects against mortality not only in healthy but also in diseased populations. ${ }^{12}{ }^{13}$ Accordingly, handgrip has been widely and increasingly recommended as a useful clinical means for stratifying individuals' risk of dying from any cause, as well as disease-specific causes, such as heart disease, and cancer. However, research on the prognostic value of handgrip strength for mortality, particularly among Korean elderly, is limited and specifically, most studies of handgrip strength in middle and old age have investigated associations with all-cause mortality, and studies that have examined cause-specific mortality are less common. 
To address this gap in the literature, we aimed to quantify the association of handgrip strength with all-cause, cardiovascular, cancer mortality in men and women from the Korean longitudinal study of ageing (KLoSA).

\section{METHODS}

\section{Patient and public involvement}

Including patient and public involvement (PPI) statements aligns closely with BMJ Open's values of transparency and inclusiveness. We hope that including PPI statements in all articles is the first step of many for BMJ Open in encouraging patient involvement.

\section{Study population}

The KLoSA is an ongoing longitudinal study that contains a nationally representative sample of the middle-aged to older Korean population living in households. A more detailed description of KLoSA can be found elsewhere. ${ }^{14}{ }^{15}$ Briefly, the baseline data were collected in 2006, with participants recruited through multistage, stratified probability sampling based on the 2005 census enumeration districts. A total of 10254 respondents aged 45 years and over completed the baseline evaluation, which included sociodemographic characteristics, medical history and measurement of cognitive function. After the baseline interview, follow-up interviews took place at regular 2-year intervals in 2008, 2010, 2012 and 2014.

From the original sample, all participants aged 50 years or older were selected. Of the remaining 8465 individuals, we excluded those with missing baseline data $(n=1695)$. Additionally, we restricted our analysis to persons whose data on handgrip strength were available on at least two occasions in order to account for the variability in handgrip strength measurements over time using time-dependent Cox regression. These restrictions resulted in a final sample of 2668 men and 3191 women $(\mathrm{n}=5859)$.

\section{Assessment of handgrip strength}

Handgrip strength was recorded to the nearest 0.125 $\mathrm{kg}$ using a handheld dynamometer (Tanita 6103, Tanita Corp., Tokyo, Japan). Participants were instructed to squeeze the handle of the dynamometer as hard as they could while seated, with their elbow flexed at $90^{\circ}$, and the forearm and wrist in neutral position. Two trials were recorded for each hand and the average of all four measures was used for analyses. ${ }^{16}$ Individuals were further classified into tertiles according to their handgrip strength score: tertile $1, \leq 20.250 \mathrm{~kg}$; tertile 2 , from 20.375 to $28.875 \mathrm{~kg}$; and tertile 3 , from 29.000 to $60.250 \mathrm{~kg}$.

\section{Ascertainment of mortality}

We followed all those included in the sample for the next four waves (waves 2-5) to verify their vital status. Information on mortality and date of death were ascertained based on a variable that recorded participants' year and date of death taken from the respondent's exit interview. The causes of death were also obtained during the exit interview, in which a proxy informant-usually the spouse, child or a close relative of the deceased respondent-who is knowledgeable about the family and the deceased were asked to report the main cause of death as listed on death certificates. For the purpose of this study, participants were followed up until death or until the date of censoring (31 December 2014) for those who were alive, whichever occurred first.

\section{Potential confounding variables}

Based on our knowledge of the existing literature on factors associated with the reduction in muscle strength and mortality and on statistical criteria (variables showing $\mathrm{p}<0.05$ in the univariate analyses), the following potential confounding variables were selected for inclusion in the multivariable Cox model: age,${ }^{17}$ gender, ${ }^{17}$ educational attainment, ${ }^{18}$ total household income,${ }^{18}$ smoking status, ${ }^{18}$ physical activity, ${ }^{19}$ body mass index (BMI) ${ }^{20}$ alcohol consumption, ${ }^{10}$ comorbidities, ${ }^{12} 1921$ cognitive function, ${ }^{22}{ }^{23}$ depressive symptoms ${ }^{12}{ }^{24}$ and social participation. ${ }^{22} 25$

Information on demographics (age, sex, education and total household income), health-related behaviours and conditions (smoking status, alcohol consumption, physical activity, BMI, comorbidities and cognitive function), mental health and social activities were collected during a face-to-face interview with computer-assisted personal interviewing. Age was measured in years and was included in the analyses as a continuous variable. Gender was dummy coded as $0=$ male, $1=$ female. Participants' educational attainment was categorised as (1) elementary school or under, (2) middle school, (3) high school completed and (4) college or above. Total household income was also categorised into four groups based on quartiles (low, middle low, middle high, high). Respondents were categorised according to their smoking status as (1) never smoker, (2) former smokers and (3) current smokers. Physical activity was assessed by asking the participant whether they engaged in any type of exercise at least once a week $(0=\mathrm{Yes}, 1=\mathrm{No})$. BMI was calculated from body weight and height, and participants were classified as underweight $(\mathrm{BMI}<18.5)$, normal $(18.5 \leq \mathrm{BMI}<23)$, overweight $(23 \leq \mathrm{BMI}<25)$ and obese $(\mathrm{BMI} \geq 25)$ according to the revised Asia-Pacific BMI criteria by the WHO Western Pacific Region. ${ }^{26}$ Participants were asked to indicate whether they consume any alcohol with the following question 'Do you sometimes or often drink any alcoholic beverages, such as beer, wine or liquor?' responding $0=$ No or $1=$ Yes. Presence of chronic diseases was assessed by self-reported doctor diagnosis of eight medical conditions. Participants were asked to respond to the following question: 'Has a doctor ever told you that you have hypertension, diabetes, cancer, chronic lung disease, liver disease, cardiovascular disease, cerebrovascular disease and arthritis?'. The total number of comorbid conditions was summed and dichotomised into two groups: none or 
one or more conditions. Cognitive function was measured with the Korean version of the Mini-Mental Status Examination (K-MMSE). Scores range from 0 to 30, with higher scores indicating better cognitive function. ${ }^{27}$ Depressive symptoms were assessed using the Korean translation of the 10-item short-form Center for Epidemiological Studies-Depression (CES-D10) Scale. ${ }^{28}$ The CES-D10 assesses self-reported depressive symptoms experienced during the 2 weeks prior to testing; the scale includes two positively phrased items ('feel pretty good' and 'generally satisfied') and eight negatively phrased items (eg, 'feel afraid'). Each item is scored from 0 to 3; (0) very rarely or less than once per day; (1) sometimes or 1-2 days during the past week; (2) often or 3-4 days during the past week; and (3) almost always or 5-7 days during the past week. All positively phrased items were reverse-coded and the scores for the 10 items were summed to obtain the total score of CES-D (range: 0-30 points). Scores of 10 and higher denotes significant depressive symptoms. ${ }^{29}$ With regard to social participation, individuals were asked to report their engagement in seven types of social activities using the question: 'Do you participate in any of the following activities?' (1) religious activities, (2) friendship gatherings (eg, senior centres), (3) leisure activities (eg, leisure, culture, sports classes), (4) alumni activities (eg, school or hometown alumni, clan meetings), (5) volunteer activities, (6) public activities (eg, political parties, civic groups, profitable organisations) and (7) other activities. Each question could be answered yes-or-no and the total number of formal social activities was summed and categorised as 0 (no participation), 1 or $\geq 2$. All covariates were measured at baseline and at each of the follow-up surveys, except for age and sex which were measured only at baseline.

\section{Statististical analyses}

All data were analysed using SAS Statistical Software V.9.4. Baseline characteristics were presented as mean \pm SD or percentages. Characteristics were compared according to baseline handgrip strength tertiles and vital status at the end of follow-up, using Pearson's $\chi^{2}$ test for categorical variables and analysis of variance for continuous variables. Time-dependent Cox proportional hazard models were used to estimate HRs and their 95\% CIs for all-cause mortality, comparing the handgrip strength categories, with the reference group being participants in the highest tertile. The cause-specific hazards regression analysis was also used to model cardiovascular diseases (CVD) and cancer mortality, by treating deaths from the cause of interest as events and other causes of death as censored. ${ }^{30}{ }^{31}$ Four multivariable models were presented to adjust confounding: model 1 adjusted for baseline age and sex; model 2 adjusted for age, sex, education and quartiles of total household income; model 3 adjusted for time-varying smoking status, physical activity, alcohol consumption and obesity in addition to the variables in model 2; model 4 adjusted for self-reported doctor diagnosis of comorbidities, depressive symptoms and engagement in social activities in addition to the variables in model 3. Additionally, we repeated analyses excluding who died within 2 years of follow-up in model 5 to assess the possibility of reverse causation. Furthermore, as descriptive statistics pointed to a significant difference in handgrip strength by age and gender (mean $\pm \mathrm{SD}$ of handgrip strength for males and females were 31.8 \pm 6.6 and $19.3 \pm 4.7 \mathrm{~kg}$, respectively), we included multiplicative interaction terms along with the main effect in our Cox models, in attempt to assess possible effect modification by gender and age groups $(<60$ and $\geq 60$ years). However, we found no evidence that the associations between handgrip strength and mortality differed by gender or age groups (all p-interaction $>0.05$ ). Hence, results obtained from the pooled sample are presented. Results of gender-specific analyses are shown in online supplementary table 1 .

\section{RESULTS}

\section{General characteristics of the study population}

Overall demographic and baseline health-related characteristics of the 5859 participants and stratified by tertiles of handgrip strength are shown in table 1 . Mean age was 63.2 years; $45.5 \%$ were men. The sample was fairly evenly distributed with respect to baseline total household income. Over half of the participants reported completing elementary level education $(51.0 \%), 17.6 \%$ were middle school graduates, $23.6 \%$ were high school graduates and $7.8 \%$ had completed a university degree or higher. The percentage of subjects smoking at baseline was $19.1 \%$, $10.8 \%$ were former smoker and $70.1 \%$ never smoked. About $62.4 \%$ identified themselves as non-drinkers and $39.4 \%$ reported engaging in regular physical exercise. About 24.2\% were classified as obese, $29.3 \%$ were classified as overweight, $42.9 \%$ were classified as normal weight and $3.6 \%$ were classified as underweight. The mean K-MMSE score was 25.1 \pm 4.3 . Approximately half (50.1\%) reported one or more comorbidities and nearly one-fifth of participants (19.4\%) met the CES-D10 criteria for depressive disorder. Study participants with lower handgrip strength tended to be older, female, never-smokers, be of lower socioeconomic status, less physically active, less likely to consume alcohol on a daily basis, report lower K-MMSE score, have higher prevalence of depressive symptoms and doctor-diagnosed chronic diseases, and less likely to participate in social activities than those with higher handgrip strength (all $\mathrm{p}<0.001$ ).

Table 2 shows baseline characteristics of the study population in relation to vital status at follow-up. A higher proportion of survivors were female, and younger. The mean age of the survivors was $62.4 \pm 8.4$ years, whereas the mean age of the deceased group was $71.0 \pm 9.3$ years $(p<0.001)$. The non-survivors had significantly higher proportion of those with elementary school education $(65.4 \%$ vs $49.6 \%)$ and low total household income $(39.6 \%$ vs $24.6 \%)$. In addition, the people who died during the observation period more likely to be current 
Table 1 Baseline characteristics of the study population according to handgrip strength, Korean longitudinal study of ageing

\begin{tabular}{|c|c|c|c|c|c|}
\hline \multirow[b]{4}{*}{ Characteristics (n, \%) } & \multirow[b]{3}{*}{ Overall } & \multicolumn{3}{|c|}{ Handgrip strength } & \multirow[b]{4}{*}{$P$ value } \\
\hline & & Tertile 1 & Tertile 2 & Tertile 3 & \\
\hline & & $(\leq 20.25 \mathrm{~kg})$ & $(20.375-28.875 \mathrm{~kg})$ & $(29.00-60.25 \mathrm{~kg})$ & \\
\hline & $n=5859$ & $\mathrm{n}=1972$ & $n=1930$ & $\mathrm{n}=1957$ & \\
\hline Age (years, mean $\pm S D$ ) & $63.2(8.83)$ & $66.7(9.10)$ & $62.2(8.56)$ & $60.6(7.59)$ & $<0.001$ \\
\hline \multicolumn{6}{|l|}{ Sex } \\
\hline Male & $2668(45.5)$ & $128(6.5)$ & $656(34.0)$ & $1884(96.3)$ & \multirow[t]{2}{*}{$<0.001$} \\
\hline Female & $3191(54.5)$ & $1844(93.5)$ & $1274(66.0)$ & $73(3.7)$ & \\
\hline \multicolumn{6}{|l|}{ Educational attainment } \\
\hline Elementary school & $2990(51.0)$ & $1457(73.9)$ & 995 (51.6) & $538(27.5)$ & \multirow[t]{4}{*}{$<0.001$} \\
\hline Middle school & $1030(17.6)$ & 262 (13.3) & $394(20.4)$ & $374(19.1)$ & \\
\hline High school & $1379(23.6)$ & $213(10.8)$ & $423(21.9)$ & $743(38.0)$ & \\
\hline University degree or above & $460(7.8)$ & $40(2.0)$ & $118(6.1)$ & $302(15.4)$ & \\
\hline \multicolumn{6}{|l|}{ Total household income } \\
\hline Q1 (low) & $1517(25.9)$ & $680(34.5)$ & $466(24.2)$ & $371(18.9)$ & \multirow[t]{4}{*}{$<0.001$} \\
\hline Q2 (middle-low) & $1382(23.5)$ & $524(26.6)$ & 480 (24.9) & 378 (19.3) & \\
\hline Q3 (middle-high) & $1462(25.0)$ & $414(21.0)$ & $501(25.9)$ & $547(28.0)$ & \\
\hline Q4 (high) & $1498(25.6)$ & $354(17.9)$ & $483(25.0)$ & $661(33.8)$ & \\
\hline \multicolumn{6}{|l|}{ Smoking status } \\
\hline Never smoker & $4106(70.1)$ & $1822(92.4)$ & 1475 (76.4) & 809 (41.3) & \multirow[t]{3}{*}{$<0.001$} \\
\hline Former smoker & $631(10.8)$ & $46(2.3)$ & $167(8.7)$ & $418(21.4)$ & \\
\hline Current smoker & $1122(19.1)$ & $104(5.3)$ & $288(14.9)$ & $730(37.3)$ & \\
\hline \multicolumn{6}{|l|}{ Alcohol consumption } \\
\hline No & $3658(62.4)$ & $1645(83.4)$ & $1316(68.2)$ & $697(35.6)$ & \multirow[t]{2}{*}{$<0.001$} \\
\hline Yes & $2201(37.6)$ & $327(16.6)$ & $614(31.8)$ & $1260(64.4)$ & \\
\hline \multicolumn{6}{|l|}{ Physical activity } \\
\hline Yes & $2306(39.4)$ & $620(31.4)$ & 767 (39.7) & $919(47.0)$ & \multirow[t]{2}{*}{$<0.001$} \\
\hline No & $3553(60.6)$ & $1352(68.6)$ & $1163(60.3)$ & $1038(53.0)$ & \\
\hline \multicolumn{6}{|l|}{ Obesity } \\
\hline Underweight & $211(3.6)$ & $114(5.8)$ & $55(2.9)$ & $42(2.2)$ & \multirow[t]{4}{*}{$<0.001$} \\
\hline Normal & $2511(42.9)$ & $899(45.6)$ & 848 (43.9) & $764(39.0)$ & \\
\hline Overweight & $1719(29.3)$ & 477 (24.2) & $587(30.4)$ & $655(33.5)$ & \\
\hline Obese & $1418(24.2)$ & $482(24.4)$ & $440(22.8)$ & $496(25.3)$ & \\
\hline \multicolumn{6}{|l|}{ Chronic illness } \\
\hline 0 & $2930(50.1)$ & 755 (38.3) & $978(50.7)$ & $1197(61.2)$ & \multirow[t]{2}{*}{$<0.001$} \\
\hline$\geq 1$ & $2929(49.9)$ & $1217(61.7)$ & $952(49.3)$ & $760(38.8)$ & \\
\hline \multicolumn{6}{|l|}{ Participation in social activities } \\
\hline 0 (No participation) & $1564(26.7)$ & $658(33.4)$ & $496(25.7)$ & $410(21.0)$ & \multirow[t]{3}{*}{$<0.001$} \\
\hline 1 & $2707(46.2)$ & $954(48.4)$ & $946(49.0)$ & 807 (41.2) & \\
\hline$\geq 2$ & $1588(27.1)$ & $360(18.2)$ & $488(25.3)$ & $740(37.8)$ & \\
\hline \multicolumn{6}{|c|}{ Depressive symptoms (CES-D $\geq 10$ ) } \\
\hline No & $4724(80.6)$ & $1365(69.2)$ & 1599 (82.9) & $1760(89.9)$ & \multirow[t]{2}{*}{$<0.001$} \\
\hline Yes & $1135(19.4)$ & $607(30.8)$ & $331(17.1)$ & $197(10.1)$ & \\
\hline $\begin{array}{l}\text { Cognitive function } \\
\text { (K-MMSE score) }\end{array}$ & $25.1(4.31)$ & $23.1(5.13)$ & $25.4(3.89)$ & $26.9(2.55)$ & \\
\hline
\end{tabular}

CES-D, Center for Epidemiological Studies-Depression; K-MMSE, Korean version of the Mini-Mental Status Examination; Q, quartile. 
Table 2 Baseline characteristics of study participants according to vital status at the end of the follow-up, Korean longitudinal study of ageing

\begin{tabular}{|c|c|c|c|}
\hline \multirow[b]{3}{*}{ Characteristics (n, \%) } & \multicolumn{2}{|c|}{ Mortality status } & \multirow[b]{3}{*}{$P$ value } \\
\hline & Deceased & Survivors & \\
\hline & $\mathrm{n}=515$ & $n=5344$ & \\
\hline Age (years, mean $\pm S D$ ) & $71.0(9.26)$ & $62.4(8.41)$ & $<0.001$ \\
\hline \multicolumn{4}{|l|}{ Sex } \\
\hline Male & 307 (59.6) & $2361(44.2)$ & \multirow[t]{2}{*}{$<0.001$} \\
\hline Female & $208(40.4)$ & $2983(55.8)$ & \\
\hline \multicolumn{4}{|l|}{ Educational attainment } \\
\hline Elementary school & $337(65.4)$ & $2653(49.6)$ & \multirow[t]{4}{*}{$<0.001$} \\
\hline Middle school & $78(15.2)$ & $952(17.8)$ & \\
\hline High school & 79 (15.3) & $1300(24.3)$ & \\
\hline University degree or above & $21(4.1)$ & 439 (8.3) & \\
\hline \multicolumn{4}{|l|}{ Total household income } \\
\hline Q1 (low) & $204(39.6)$ & $1313(24.6)$ & \multirow[t]{4}{*}{$<0.001$} \\
\hline Q2 (middle-low) & $141(27.4)$ & $1241(23.2)$ & \\
\hline Q3 (middle-high) & $93(18.1)$ & 1369 (25.6) & \\
\hline Q4 (high) & 77 (14.9) & $1421(26.6)$ & \\
\hline \multicolumn{4}{|l|}{ Smoking status } \\
\hline Never smoker & $294(57.1)$ & 3812 (71.3) & \multirow[t]{3}{*}{$<0.001$} \\
\hline Former smoker & $78(15.2)$ & $553(10.4)$ & \\
\hline Current smoker & $143(27.7)$ & 979 (18.3) & \\
\hline \multicolumn{4}{|l|}{ Alcohol consumption } \\
\hline No & $323(62.7)$ & $3335(62.4)$ & 0.89 \\
\hline Yes & $192(37.3)$ & 2009 (37.6) & \\
\hline \multicolumn{4}{|l|}{ Physical activity } \\
\hline Yes & $151(29.3)$ & $2155(40.3)$ & \multirow[t]{2}{*}{$<0.001$} \\
\hline No & $364(70.7)$ & $3189(59.7)$ & \\
\hline \multicolumn{4}{|l|}{ Obesity } \\
\hline Underweight & $49(9.5)$ & $162(3.0)$ & \multirow[t]{4}{*}{$<0.001$} \\
\hline Normal & $262(50.9)$ & $2249(42.1)$ & \\
\hline Overweight & $119(23.1)$ & $1600(29.9)$ & \\
\hline Obese & $85(16.5)$ & $1333(25.0)$ & \\
\hline \multicolumn{4}{|l|}{ Chronic illness } \\
\hline 0 & $201(39.0)$ & $2729(51.1)$ & \multirow[t]{2}{*}{$<0.001$} \\
\hline$\geq 1$ & $314(61.0)$ & 2615 (48.9) & \\
\hline \multicolumn{4}{|l|}{ Participation in social activities } \\
\hline 0 (No participation) & 207 (40.2) & $1357(25.4)$ & \multirow[t]{3}{*}{$<0.001$} \\
\hline 1 & $218(42.3)$ & 2489 (46.6) & \\
\hline$\geq 2$ & $90(17.5)$ & $1498(28.0)$ & \\
\hline \multicolumn{4}{|l|}{ Depressive symptoms (CES-D $\geq 10$ ) } \\
\hline No & $349(67.8)$ & 4375 (81.9) & \multirow[t]{2}{*}{$<0.001$} \\
\hline Yes & $166(32.2)$ & $969(18.1)$ & \\
\hline Cognitive function (K-MMSE score) & $22.8(5.51)$ & $25.4(4.11)$ & $<0.001$ \\
\hline
\end{tabular}




\begin{tabular}{|c|c|c|c|}
\hline \multirow[b]{3}{*}{ Characteristics (n, \%) } & \multicolumn{2}{|c|}{ Mortality status } & \multirow[b]{3}{*}{$P$ value } \\
\hline & Deceased & Survivors & \\
\hline & $n=515$ & $\mathrm{n}=5344$ & \\
\hline Tertile 2 (middle) & $135(26.2)$ & 1795 (33.6) & \\
\hline Tertile 3 (high) & $152(29.5)$ & 1805 (33.8) & \\
\hline
\end{tabular}

CES-D, Center for Epidemiological Studies-Depression; K-MMSE, Korean version of the Mini-Mental Status Examination; Q, quartile.

smokers $(27.7 \%$ vs $18.3 \%)$, categorised as inactive physically $(70.7 \%$ vs $59.7 \%)$ and meet criteria for depressive symptoms (32.2\% vs $18.1 \%)$ compared with those who were alive. The non-survivor group had a significantly higher percentage of those categorised as underweight $(9.4 \%$ vs $3.0 \%)$ and lower proportion of overweight/ obese individuals. Also, the deceased were more likely to belong to the low handgrip strength tertile $(44.3 \%$ vs $32.6 \%$ ), report lower K-MMSE scores (mean score 22.8 vs 25.4), report one or more comorbidities and less likely to participate in social activities than survivors. No statistical difference between the two groups was found for alcohol consumption $(\mathrm{p}=0.89)$.

\section{Association of handgrip strength with all-cause mortality}

During 46660 person-years (mean $7.9 \pm 0.91$ years) of follow-up, 515 individuals (8.8\%) died, reflecting an overall crude mortality rate of 11.0 deaths per 1000 person-years. Of these, 123 participants died from cardiovascular causes and 140 participants from cancer. Table 3 summarises number of death events, mortality rates across tertiles of handgrip strength and the HRs for all-cause mortality derived from time-dependent Cox proportional hazard models. From the highest tertile to the lowest, the mortality rates were $9.7,8.7$ and 14.6 per 1000 personyears, respectively. As compared with participants in the highest tertiles of handgrip strength, individuals in the lowest tertile had nearly threefold higher risk of death after adjustment for age and sex (HR=2.73; 95\% CI 1.96 to 3.79). After accounting for socioeconomic factors, similar associations between the handgrip strength categories and all-cause mortality were attenuated but remained statistically significant in model 2 (HR: 2.57, 95\% CI 1.84 to 3.60). Further adjustment for behavioural risk factors did not substantially change the associations (model $3)$. Individuals in the lowest tertile had approximately 2.3-fold higher risk of all-cause mortality compared with those in the highest tertile (HR: 2.27, 95\% CI 1.62 to 3.19). In the fully adjusted model, after controlling for sociodemographic characteristics, behavioural risk factors, comorbid conditions, cognitive function, depressive symptoms and engagement in social activities, handgrip strength remained independently associated with higher rates of death. Multivariable adjusted HR for all-cause death for every $1 \mathrm{~kg}$ decrease in handgrip strength was $1.05,95 \%$ CI 1.03 to 1.07 . There was also a significant inverse linear trend in all-cause mortality across categories of handgrip strength ( $p$ trend $<0.001$ for all models). Individuals in the lowest tertile of handgrip strength had adjusted HR of 1.90 (95\% CI 1.33 to 2.73), compared with those in the highest tertile. Sensitivity analysis showed no important changes in HRs with exclusion of those who died within first 2 years of follow-up (model 5 ).

\section{Association of handgrip strength with CVD and cancer mortality}

We used cause-specific hazard regression models to examine the associations of CVD and cancer mortality with handgrip strength (table 4). After adjusting for age, sex and the competing risk of non-cardiovascular deaths, HRs for CVD mortality across tertiles of handgrip strength were 1.27 (95\% CI 0.93 to 1.74) for the middle tertile, and 1.88 (95\% CI 1.31 to 2.71) for the lowest tertile of muscular strength versus the reference group (highest tertile) ( $p$ trend $<0.001)$. Although attenuated on adjustment for socioeconomic factors, the association between handgrip strength and CVD mortality persisted, with a $73 \%$ excess CVD mortality (HR: $1.73,95 \%$ CI 1.20 to 2.50 ) among the lowest handgrip strength tertile as compared with highest tertile (model 2). There was a substantial reduction in the strength of the relationship after including smoking status, physical activity, alcohol consumption and obesity into the model (HR: $1.55,95 \%$ CI 1.07 to 2.26) (model $3)$. In the fully adjusted model, the risk associated with being in the lowest tertile of handgrip strength was still substantial and statistically significant after further adjustment for self-reported doctor diagnosis of comorbidities, cognitive function, depressive symptoms and engagement in social activities (model 4). In the model evaluating handgrip strength as a continuous variable, the risk of death from CVD decreased continuously with handgrip strength (fully adjusted HR for $1 \mathrm{~kg}$ decrement 1.02, $95 \%$ CI 1.01 to 1.04 ).

As for cancer-related deaths, being in the lowest tertile of handgrip strength was inversely related to risk of cancer mortality compared with the highest tertile (HR: $1.57,95 \%$ CI 1.15 to 2.15 ) after adjusting for age and sex. After additional adjustment for education and total household income, the effect of handgrip strength was attenuated (adjusted HR for lowest vs highest tertile, HR: 1.51 [95\% CI 1.10 to 2.07]) and this association was of marginal significance, once smoking status, physical 
activity, alcohol consumption and obesity were taken into account. Finally, model 4 in table 4 shows that there was no longer a statistically significant relationship between handgrip strength and subsequent cancer mortality after adjusting for comorbidities, depressive symptoms, engagement in social activities and other covariates (fully adjusted HR for $1 \mathrm{~kg}$ decrement 1.01, 95\% CI 1.00 to 1.03 ; HR for lowest vs highest tertile, HR: 1.29 [95\% CI 0.92 to $1.81])$.

\section{DISCUSSION}

\section{Study findings and comparison with other studies}

In this large population-based study of community-dwelling Korean elderly followed over 8 years, we found reduced handgrip strength to be associated with significantly higher rates of all-cause mortality. These associations were similar across gender and age groups and were not fully explained by adjustment for various sociodemographic, lifestyle-related and health-related factors.

Our findings of a significant relation between all-cause mortality and handgrip strength are in agreement with results from a meta-analysis of 42 prospective cohort studies including over 3 million participants, which reported that a lowest category was, after multivariable adjustment, associated with a HR of 1.41 for all-cause mortality. ${ }^{11}$ The Prospective Urban-Rural Epidemiology study reported a similar finding in adults aged $35-70$ years, residing in 17 countries of various income levels. ${ }^{32}$ Other studies have also investigated the association between handgrip strength and mortality in the general population. For example, in the Hisayama study in Japan, multivariable-adjusted $\mathrm{HRs}(95 \% \mathrm{CI})$ for all-cause death was $0.50(0.40$ to 0.62$)$ for tertile 2 and 0.41 (0.32 to 0.51$)$ for tertile 3 compared with the lowest-tertile group, among those aged 65 years or older. ${ }^{33}$

As for cause-specific mortality, results for CVD deaths resembled that of all-cause mortality, while the relation between cancer mortality and handgrip strength was not significant in the fully adjusted analyses. These findings are in line with the results obtained from the UK Biobank Study, ${ }^{34}$ which followed 420727 individuals for 6 years (HR tertile 1 vs $3=1.38,95 \%$ CI 1.18 to 1.62 ) and the Tromsø Study, ${ }^{9}$ which followed 6850 participants for 17 years (HR=1.14, 95\% CI 1.06 to 1.22$)$. These studies reported a similar inverse association between handgrip strength and CVD mortality. In a study of Japanese community-dwelling older adults, Kishimoto $e t a l^{33}$ found no significant association between cancer-related deaths and handgrip strength (HR=1.43, 95\% CI 0.93 to 2.18). Recently, findings from a study which had measures of handgrip strength in almost 477074 participants aged 40-69 years were reported. ${ }^{35}$ This study conducted in the UK also failed to show a statistically significant relation between handgrip strength and cancer mortality.

With so many influences contributing to handgrip strength and mortality, the detailed mechanisms underlying the association remain unclear, but they are likely 


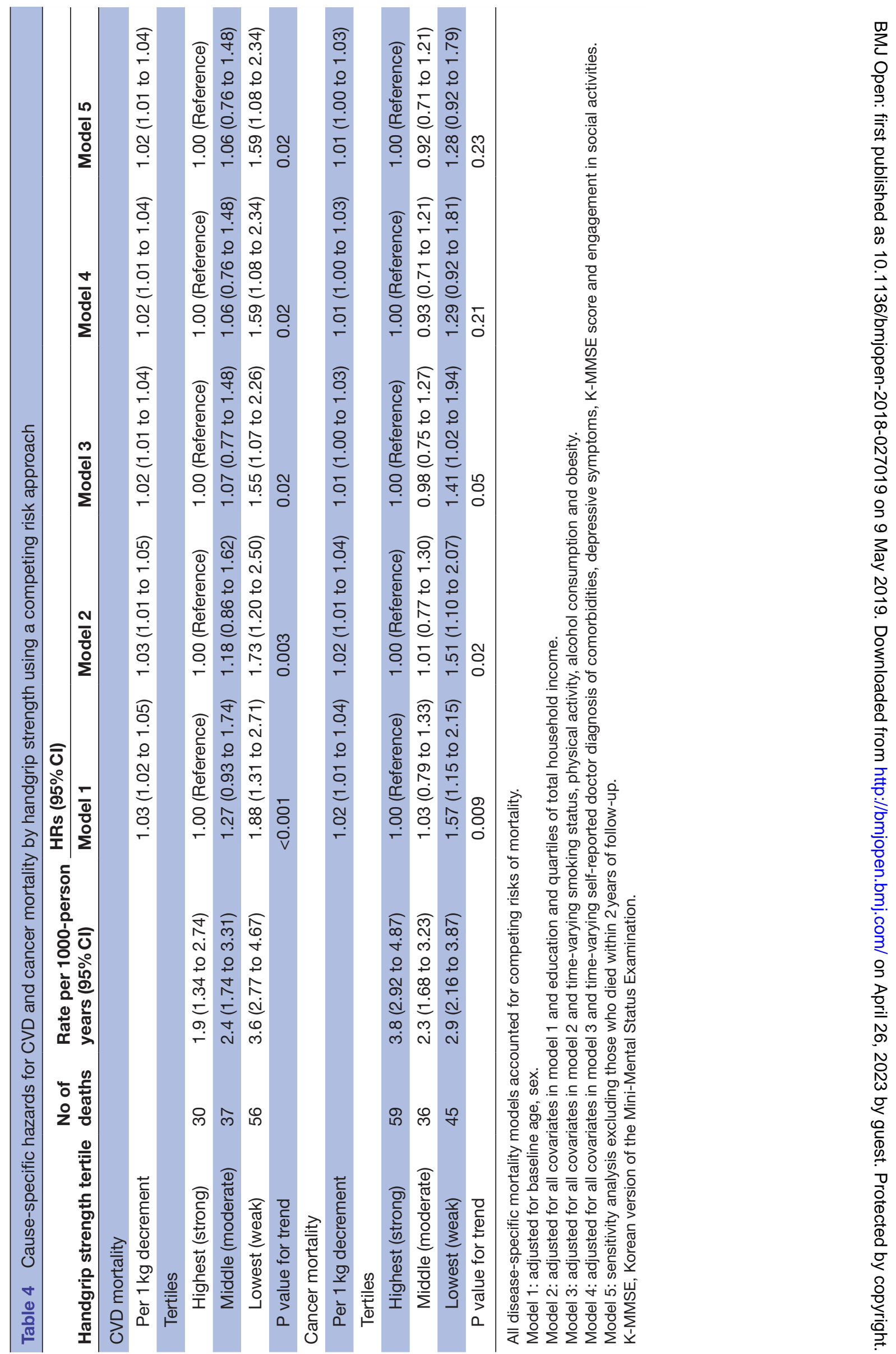


to be multifaceted in nature and are worthy of further research. One such mechanism may be through endocrine system modulation. During the last decade, skeletal muscle has been recognised as a secretory organ producing and expressing mytokines and peptides, such as IL-6 and brain-derived neurotrophic factor, in response to contraction. ${ }^{36}{ }^{37}$ Mytokines can affect the regulation of glucose and lipid metabolism thus contributing to the pathogenesis of obesity, diabetes and other metabolic disorders. Furthermore, myokines play a pivotal role in counteracting the harmful effects of proinflammatory adipokines. ${ }^{38}$ Indeed, robust associations between chronic low-grade inflammation and sarcopenia have been observed, and recent studies have shown that circulatory concentrations of inflammatory biomarkers are significantly elevated in elderly persons with lower levels of muscular strength. ${ }^{39-41}$ Low-grade inflammation is ultimately related to the risk of mortality. ${ }^{43}$ Additionally, the results of an association between handgrip strength and cardiovascular mortality and absence of association for cancer-related deaths, suggest a potential mechanism related to the cardiovascular system, which should be further explored.

\section{Study limitations and strengths}

A key strength of this study is the prospective design with repeated covariate measurements and the adjustment for competing risk for death from other causes, which allowed for unbiased estimation of the incidence of cause-specific mortality over time. Other strengths of this study include the use of objective and standardised test for the assessment of muscular strength and the nationally representative population-based sample.

There are number of limitations to this study. First, prior work has demonstrated gender-specific relationship between handgrip strength and mortality. ${ }^{44}$ However, given the relatively small sample size, gender-specific analyses did not produce statistically significant results in our study, particularly for cause-specific mortality. These null results may be due to an underpowered sample and future studies based on larger sample size are needed to reliably examine the potential gender dimensions, as well as the mechanisms behind the association. Second, we undertook analyses using cause-specific mortality; however, because of small numbers of deaths, these analyses were restricted to cardiovascular and cancer mortality. Third, although we have adjusted for various confounding factors such as age, physical activity, chronic diseases and engagement in social activities, we cannot exclude the possibility of residual confounding from other relevant covariates which remains unaccounted for in our analyses. For example, previous studies have indicated that nutrient intake is associated with the risk of mortality ${ }^{45}$ and handgrip strength. ${ }^{46}$ However, we were unable to control for nutritional status due to lack of nutrition data in KLoSA. In addition, several of the covariates were defined based on self-reported data. Socially less desirable behaviours such as smoking and physical inactivity are likely to be under-reported, and are therefore subject to recall bias. Non-response and loss to follow-up could also have contributed to biased estimation of the association between handgrip strength and mortality, if such loss is associated with both mortality risk and handgrip strength. Similarly, the use of proxy-provided causes of death is subject to measurement bias and must be assessed with caution. Nonetheless, to our knowledge, KLoSA is one of the few sources to longitudinally study the determinants of health of the ageing Korean population, with information on mortality. Finally, as with any observational study, we could only assess statistical associations and not causal relationships. Ideally, intervention studies designed to enhance muscular strength in older adults have to show whether the observed associations are truly causal and whether premature deaths can be prevented by increasing muscular strength in the long term. Nevertheless, additional analysis showed no substantial changes in the results after excluding deaths within the first 2 years of observation; this argues against a reverse causation bias. Importantly, the presence of a graded association further supports the existence of a genuine association between handgrip strength and mortality.

\section{CONCLUSIONS}

Despite these potential limitations, the present findings remain important by providing evidence that reduced handgrip strength, a marker of muscle weakness, is associated with increased rates of all-cause mortality and deaths due to cardiovascular diseases among Korean older adults, independent of various other risk factors examined. Timely assessment of handgrip strength may, therefore, be useful in identifying individuals at increased risk for premature mortality.

Contributors GRK and CMN contributed to the conception and design of the study GRK, JS and MH contributed to analyses and interpretation of the data. GRK drafted the manuscript. SP and CMN revised it critically for important intellectual content. All authors read and approved the final manuscript.

Funding The authors have not declared a specific grant for this research from any funding agency in the public, commercial or not-for-profit sectors.

Competing interests None declared.

Patient consent for publication Not required.

Provenance and peer review Not commissioned; externally peer reviewed.

Data sharing statement Data used in this study are publicly available at http:// survey.keis.or.kr.

Open access This is an open access article distributed in accordance with the Creative Commons Attribution Non Commercial (CC BY-NC 4.0) license, which permits others to distribute, remix, adapt, build upon this work non-commercially, and license their derivative works on different terms, provided the original work is properly cited, appropriate credit is given, any changes made indicated, and the use is non-commercial. See: http://creativecommons.org/licenses/by-nc/4.0/.

\section{REFERENCES}

1. Peterson MD, Duchowny K, Meng Q, et al. Low normalized grip strength is a biomarker for cardiometabolic disease and physical 
disabilities among U.S. and Chinese adults. The Journals of Gerontology: Series A 2017;72:1525-31.

2. Giampaoli S, Ferrucci L, Cecchi F, et al. Hand-grip strength predicts incident disability in non-disabled older men. Age Ageing 1999;28:283-8.

3. López-Teros T, Gutiérrez-Robledo LM, Pérez-Zepeda MU. Gait speed and handgrip strength as predictors of incident disability in mexican older adults. J Frailty Aging 2014;3:109-12.

4. Simmonds SJ, Syddall HE, Westbury LD, et al. Grip strength among community-dwelling older people predicts hospital admission during the following decade. Age Ageing 2015;44:954-9.

5. Sayer AA, Syddall HE, Martin HJ, et al. Is grip strength associated with health-related quality of life? Findings from the Hertfordshire Cohort Study. Age Ageing 2006;35:409-15.

6. Ling $\mathrm{CH}$, Taekema D, de Craen AJ, et al. Handgrip strength and mortality in the oldest old population: the Leiden 85-plus study. CMAJ 2010;182:429-35.

7. Rijk JM, Roos PR, Deckx L, et al. Prognostic value of handgrip strength in people aged 60 years and older: a systematic review and meta-analysis. Geriatr Gerontol Int 2016;16:5-20.

8. Oksuzyan A, Demakakos P, Shkolnikova M, et al. Handgrip strength and its prognostic value for mortality in Moscow, Denmark, and England. PLoS One 2017;12:e0182684.

9. Strand $\mathrm{BH}$, Cooper R, Bergland A, et al. The association of grip strength from midlife onwards with all-cause and cause-specific mortality over 17 years of follow-up in the Troms $\varnothing$ Study. J Epidemiol Community Health 2016;70:1214-21.

10. Sasaki H, Kasagi F, Yamada M, et al. Grip strength predicts causespecific mortality in middle-aged and elderly persons. Am J Med 2007;120:337-42.

11. Wu Y, Wang W, Liu T, et al. Association of grip strength with risk of all-cause mortality, cardiovascular diseases, and cancer in community-dwelling populations: a meta-analysis of prospective cohort studies. J Am Med Dir Assoc 2017:18:551.e17-551.e35.

12. Rantanen $T$, Volpato $S$, Ferrucci $L$, et al. Handgrip strength and cause-specific and total mortality in older disabled women: exploring the mechanism. J Am Geriatr Soc 2003;51:636-41.

13. Hamasaki $\mathrm{H}$, Kawashima $\mathrm{Y}$, Katsuyama $\mathrm{H}$, et al. Association of handgrip strength with hospitalization, cardiovascular events, and mortality in Japanese patients with type 2 diabetes. Sci Rep 2017;7:7041.

14. Jang S-N. Korean Longitudinal Study of Ageing (KLoSA): overview of research design and contents. Encyclopedia of Geropsychology 2015:1-9.

15. B-t O, Hwang Y-S, Lee J-Y, et al. Factors related with hand grip strength in Korean elderly. Korean J Clin Geri 2017;18:22-9.

16. Min JY, Lee KJ, Park JB, et al. Social engagement, health, and changes in occupational status: analysis of the Korean Longitudinal Study of Ageing (KLoSA). PLoS One 2012;7:e46500.

17. Budziareck MB, Pureza Duarte RR, Barbosa-Silva MC. Reference values and determinants for handgrip strength in healthy subjects. Clin Nutr 2008;27:357-62.

18. Quan S, Jeong JY, Kim DH. The relationship between smoking, socioeconomic status and grip strength among communitydwelling elderly men in korea: hallym aging study. Epidemiol Health 2013;35:e2013001.

19. Granic A, Davies K, Jagger C, et al. Grip strength decline and its determinants in the very old: longitudinal findings from the Newcastle 85+ Study. PLoS One 2016;11:e0163183

20. Lee JE, Kim KW, Paik NJ, et al. Evaluation of factors influencing grip strength in elderly koreans. J Bone Metab 2012;19:103-10.

21. Rantanen T, Masaki K, Foley D, et al. Grip strength changes over 27 yr in Japanese-American men. J Appl Physiol 1998;85:2047-53.

22. Taekema DG, Gussekloo J, Maier AB, et al. Handgrip strength as a predictor of functional, psychological and social health. A prospective population-based study among the oldest old. Age Ageing 2010;39:331-7.

23. Roberts HC, Syddall HE, Sparkes J, et al. Grip strength and its determinants among older people in different healthcare settings. Age Ageing 2014;43:241-6.

24. Rantanen T, Penninx BW, Masaki K, et al. Depressed mood and body mass index as predictors of muscle strength decline in old men. $J$ Am Geriatr Soc 2000;48:613-7.
25. Kim JH, Lee SG, Kim TH, et al. Influence of social engagement on mortality in korea: analysis of the korean longitudinal study of aging (2006-2012). J Korean Med Sci 2016;31:1020-6.

26. WHO Expert Consultation. Appropriate body-mass index for Asian populations and its implications for policy and intervention strategies. Lancet 2004;363:157-163.

27. Kang Y, DI N, Hahn S. A validity study on the Korean Mini-Mental State Examination (K-MMSE) in dementia patients. Journal of the Korean neurological association 1997;15:300-8.

28. Radloff LS. The CES-D scale: A self-report depression scale for research in the general population. Applied psychological measurement 1977;1:385-401.

29. Andresen EM, Malmgren JA, Carter WB, et al. Screening for depression in well older adults: evaluation of a short form of the CES-D. Am J Prev Med 1994:10:77-84.

30. Austin PC, Lee DS, Fine JP. Introduction to the analysis of survival data in the presence of competing risks. Circulation 2016;133:601-9.

31. Lau B, Cole SR, Gange SJ. Competing risk regression models for epidemiologic data. Am J Epidemiol 2009;170:244-56.

32. Leong DP, Teo KK, Rangarajan S, et al. Prognostic value of grip strength: findings from the Prospective Urban Rural Epidemiology (PURE) study. Lancet 2015;386:266-73.

33. Kishimoto $\mathrm{H}$, Hata J, Ninomiya $\mathrm{T}$, et al. Midlife and late-life handgrip strength and risk of cause-specific death in a general Japanese population: the Hisayama Study. J Epidemiol Community Health 2014;68:663-8.

34. Yates T, Zaccardi F, Dhalwani NN, et al. Association of walking pace and handgrip strength with all-cause, cardiovascular, and cancer mortality: a UK Biobank observational study. Eur Heart J 2017;38:3232-40.

35. Celis-Morales CA, Welsh P, Lyall DM, et al. Associations of grip strength with cardiovascular, respiratory, and cancer outcomes and all cause mortality: prospective cohort study of half a million UK Biobank participants. BMJ 2018;361:k1651.

36. Pedersen BK. Muscle as a secretory organ. Compr Physiol 2013;3:1337-62.

37. Pedersen BK, Febbraio MA. Muscle as an endocrine organ: focus on muscle-derived interleukin-6. Physiol Rev 2008;88:1379-406.

38. Trayhurn P, Drevon CA, Eckel J. Secreted proteins from adipose tissue and skeletal muscle - adipokines, myokines and adipose/ muscle cross-talk. Arch Physiol Biochem 2011;117:47-56.

39. Volaklis KA, Halle M, Koenig W, et al. Association between muscular strength and inflammatory markers among elderly persons with cardiac disease: results from the KORA-Age study. Clin Res Cardiol 2015;104:982-9.

40. Wang J, Leung KS, Chow SK, et al. Inflammation and age-associated skeletal muscle deterioration (sarcopaenia). J Orthop Translat 2017;10:94-101.

41. Schaap LA, Pluijm SM, Deeg DJ, et al. Inflammatory markers and loss of muscle mass (sarcopenia) and strength. Am J Med 2006;119:526.e9-526.e17.

42. Rathcke CN, Raymond I, Kistorp C, et al. Low grade inflammation as measured by levels of YKL-40: association with an increased overall and cardiovascular mortality rate in an elderly population. Int J Cardiol 2010:143:35-42.

43. Bonaccio M, Di Castelnuovo A, Pounis G, et al. A score of low-grade inflammation and risk of mortality: prospective findings from the Moli-sani study. Haematologica 2016;101:1434-41.

44. Arvandi M, Strasser B, Meisinger C, et al. Gender differences in the association between grip strength and mortality in older adults: results from the KORA-age study. BMC Geriatr 2016;16:201.

45. Lim J, Lee Y, Shin S, et al. An association between diet quality index for Koreans (DQI-K) and total mortality in Health Examinees Gem (HEXA-G) study. Nutr Res Pract 2018;12:258-64.

46. Robinson SM, Jameson KA, Batelaan SF, et al. Diet and its relationship with grip strength in community-dwelling older men and women: the Hertfordshire cohort study. J Am Geriatr Soc 2008;56:84-90.

47. Tak YJ, Lee JG, Yi YH, et al. Association of Handgrip Strength with Dietary Intake in the Korean Population: Findings Based on the Seventh Korea National Health and Nutrition Examination Survey (KNHANES VII-1), 2016. Nutrients 2018;10:1180. 
Correction: Impact of handgrip strength on cardiovascular, cancer and all-cause mortality in the Korean longitudinal study of ageing

Kim GR, Sun J, Han M, et al. Impact of handgrip strength on cardiovascular, cancer and all-cause mortality in the Korean longitudinal study of ageing. BMJOpen 2019;9:e027019. doi: 10.1136/bmjopen-2018-027019

This article was previously published with an error.

The correct author affiliations are as follows:

Gyu Ri Kim ${ }^{1}$, Jiyu Sun ${ }^{2}$, Minkyung Han ${ }^{3}$, Sohee Park ${ }^{1}$, Chung Mo Nam²,

${ }^{1}$ Department of Biostatistics, Graduate School of Public Health, Yonsei University, Seoul, Korea.

${ }^{2}$ Department of Biostatistics, College of Medicine, Yonsei University, Seoul, Korea.

${ }^{3}$ Department of Public Health, Graduate School, Yonsei University, Seoul, Korea.

${ }^{4}$ Department of Preventive Medicine, College of Medicine, Yonsei University, Seoul, Korea.

Open access This is an open access article distributed in accordance with the Creative Commons Attribution Non Commercial (CC BY-NC 4.0) license, which permits others to distribute, remix, adapt, build upon this work non-commercially, and license their derivative works on different terms, provided the original work is properly cited, appropriate credit is given, any changes made indicated, and the use is non-commercial. See: http://creativecommons.org/licenses/by-nc/4.0/.

(C) Author(s) (or their employer(s)) 2019. Re-use permitted under CC BY-NC. No commercial re-use. See rights and permissions. Published by BMJ.

BMJ Open 2019;9:e027019corr1. doi:10.1136/bmjopen-2018-027019corr1

A) Check for updates 